\title{
NOTE
}

\section{Role of burrows as refuges from subtidal predators of temperate mangrove crabs}

\author{
J. H. Warren* \\ Institute of Marine Ecology, Zoology Building A08, University of Sydney, NSW 2006, Australia
}

\begin{abstract}
The importance of burrows as a refuge from subtidal predators of the temperate mangrove crab Heloecius cordiformis was investigated in a field experiment at Careel Bay, New South Wales, Australia. Two experimental treatments were used: 'Deep bins' filled completely with sediment. which allowed crabs to construct burrows prior to tidal submergence, and 'Shallow bins' filled with sediment but with a plastic sheet $1 \mathrm{~cm}$ below the surface of the sediment, thus preventing crabs from excavating burrows. At each experimental trial, 74 to $100 \%$ of the crabs in Shallow bins were consumed by toadfish within $2 \mathrm{~h}$ of submergence, whereas only 13 to $23 \%$ of the crabs in Deep bins were eaten. These results suggest that entering and remaining in burrows during high tide provides an effective refuge for $H$. cordiformis against predation by toadfish and perhaps other intertidal and subtidal predators.
\end{abstract}

The importance of burrows to crabs in intertidal and supratidal environments is indicated by the prevalence of this association in a wide range of habitats: mudflats, seagrass beds, salt marshes, mangrove swamps, coastal dunes and even grasslands up to $5 \mathrm{~km}$ from the shore (Warner 1977). Although many species of crabs do not, or cannot, construct their own burrows, most are nonetheless associated with these structures.

Widely-cited functions of burrows include centres for courtship, defence of territories and other behaviours; sites for incubation and extrusion of eggs; refuges from environmental stresses (primarily desiccation); and refuges from subtidal, terrestrial or avian predators (see reviews by Crane 1975, Warner 1977, Montague 1980). Of studies on the role of burrows in providing a refuge from predation, none has actually tested the effectiveness of the burrow in reducing mortality. Several studies have, however, demonstrated that infauna buried deep within soft substrata suffer significantly less predation than populations living closer to the surface (e.g. Virnstein 1977, Blundon \& Kennedy 1982).

\footnotetext{
- Present address: Department of Marine Biology, James Cook University, Townsville, Queensland 4811, Australia
}

The present study examined the importance of burrows in reducing predation on the semaphore crab Heloecius cordiformis. This ocypodid species is abundant in temperate mangrove swamps in southeastern Australia. Similar to many of its better-known ocypodid relatives, the fiddler crabs, $H$. cordiformis is active on the surface of the substratum only during periods of tidal emersion (low tide), during daylight hours, and burrows tend to contain only a single individual (Warren 1987). At the end of their period of activity on the surface (just prior to dusk or submergence by the rising tide), crabs enter and plug their burrows with a clod of sediment (Warren \& Underwood 1986). The aim of this study was to test experimentally the prediction that $H$. cordiformis could avoid predation from epibenthic predators by sheltering in burrows during periods of tidal submergence.

Methods. The experiment was done in the temperate mangrove swamp at Careel Bay, $35 \mathrm{~km}$ north of Sydney, New South Wales, Australia. Careel Bay is located on the northeastern shore of Pittwater, an inlet which opens northerly into the Hawkesbury River/Broken Bay Estuary. Tides are semi-diurnal, with a maximum range of $1.8 \mathrm{~m}$. Seagrass beds (primarily Zostera marina and Posidonia australis) occur between the opening of Careel Bay and Pittwater and abut the seaward edge of the mangrove swamp (indicated by dense peg roots and saplings of the grey mangrove Avicennia marina). Henceforth, this zone will be referred to as the 'seaward zone' of the mangrove forest. The 'midmangrove zone' constitutes the forest proper. The lower two-thirds of this zone consists of tall $A$. marina ( 5 to $6 \mathrm{~m}$ high) with a dense and almost continuous canopy. A shorter $(<2 \mathrm{~m})$ and more shrub-like second species, the river mangrove Aegiceras corniculatum, is sporadically interspersed with $A$. marina within the landward one-third of the forest.

The experiment was done in the lower midmangrove 
zone to ensure that the water at high tide would be deep enough for subtidal carnivores to pass over and into experimental bins. Two treatments were used. In one, crabs were prevented from burrowing before they were submerged by the incoming tide. In the other treatment, crabs were capable of digging burrows. Both treatments utilised perforated plastic bins $(30 \times 45 \times 16 \mathrm{~cm}$ deep $)$. On $23 \mathrm{Sep} 1985$, a total of 8 bins was used, but on 24 and 25 Sep, an additional 4 bins were used (to allow a better estimate of variability of predation). Half of the bins used on each day were filled to a depth of $8 \mathrm{~cm}$ with sandy substratum from the upper edge of the forest (= Deep bins). The other half were filled to a depth of $7 \mathrm{~cm}$, this layer covered with a thin sheet of plastic, and an additional $1 \mathrm{~cm}$ of sand added on top of this plastic sheet (= Shallow bins). In the latter treatment, therefore, crabs could make only shallow depressions and could not hide beneath the substratum. Bins were buried such that the top edge of bins was even with the surrounding substratum, because toadfish are epibenthic feeders. Bins were randomly arranged in 2 rows parallel to the shoreline. The distance between the surface of the sediments within both types of bins and the top edge of the bins (ca $8 \mathrm{~cm}$ ) was adequate to prevent escape by crabs.

Sandy substratum from the landward edge of the forest was used for 2 reasons. In pilot experiments using the siltier sediments from the lower midmangrove zone, it was impossible to see inside bins after submergence because the water in them became murky with the suspension of fine-grained material. Sediments in the landward zone have less silt and more sand which does not re-suspend as easily as silts and clays. Also, the greater density of peg roots and nutritive roots in the lower midmangrove zone relative to the upper reaches of the forest made it difficult to create an even layer of sediment of the desired depth in the bins. An even layer was desired to avoid creating refuges which would have resulted from an attempt to mash root-laden sediments into the bins. Peg roots and nutritive roots are less dense in the upper edge of the forest, and peg roots could be more easily removed from these sediments. The only refuges that were possible in the bins were, therefore, ones created by the crabs themselves. Heloecius cordiformis are as abundant in this upper zone as in the lower midmangrove zone (Warren 1987); therefore, this modification did not present an ecologically irrelevant type of substratum to the experimental animals. Although handling of sediments placed in bins increased the tendency of the surface sediments to become resuspended (relative to natural, undisturbed sediments), this tendency should have been similar between the 2 experimental treatments.

One hour before submergence, 20 crabs were added to each bin. Crabs had been collected and marked in the field with a spot of white latex paint (to improve detectability in the bins) before being put in the bins An approximately equal number of males and females (from 15 to $25 \mathrm{~mm}$ carapace length) were used in each bin. The experimental density was approximately $3 \times$ natural mean densities ( 148 vs $44 \mathrm{crabs}^{-2}$ ) but was within the observed range of densities sampled over a 14 mo period (Warren 1987). The experimental density, however, did not appear to interfere with the ability of crabs to build viable burrows, as virtually all crabs in Deep bins were able to construct, enter and plug burrows within $1 \mathrm{~h}$ of being added to bins. Substratum in bins did not collapse during any experimental trial, further suggesting that the burrows constructed were stable (i.e. viable).

During the period of submergence, observers recorded the numbers of crabs in each bin that were eaten and the species of predator taking each crab. Each observer was responsible for recording events in 4 bins (2 Deep and 2 Shallow bins). Observers sat as still as possible on stools placed adjacent to bins before the tide rose over them. At the end of the $2 \mathrm{~h}$ period of observation, bins were collected, and surviving crabs were extracted from the sediments and counted. The difference between the initial numbers of crabs and the numbers that were eaten or were re-collected from bins was attributed to crabs that were missing, either because they had escaped (which was unlikely) or because they were not seen being eaten.

A 2-factor analysis of variance (ANOVA) was used to test effects of each type of bin (fixed factor), differences among days of the experiment (fixed factor, because days consecutive), and interaction between these 2 factors. To retain a balanced design, the additional 2 replicate bins used on 22 and 23 Sep were not included in this analysis. Student Newman Keuls test was used to identify which means differed significantly from others for factors shown to be significant in the analysis of variance.

Results. The only subtidal predators observed during the 3 runs of the experiment were toadfish $(10$ to $15 \mathrm{~cm}$ in length). These entered the midmangrove zone within 15 min of submergence, although the water was only 10 to $15 \mathrm{~cm}$ deep at this time. They entered bins and began to attack crabs on the surface almost immediately. When toadfish entered bins, crabs that were on the surface of the sediments assumed a defensive stance, with open chelae extended outwards Because of this, fish could not immediately seize a crab but would approach from several angles until the fish could grab the crab's body whilst avoiding its chelae. Frequently, more than 1 fish would simultaneously approach a crab from different angles, and this made it easier for at least 1 toadfish to seize the prey. Large 
crabs (> $20 \mathrm{~mm}$ ) appeared to take longer to capture than smaller crabs; however, large size did not provide a refuge for Heloecius cordiformis.

Toadfish entered but did not remain long in bins without crabs on the surface. Occasionally, fish stirred up the first few $\mathrm{mm}$ of sediment in such bins (by blowing water or rapidly waving the tail close to the substratum) and then re-examined the surface. In Deep bins, occasionally 1 or 2 crabs were still on the surface or re-emerged after being covered by the tide. No crabs were seen to escape from bins.

Analysis of variance indicated that significantly more crabs were eaten in Shallow bins than Deep bins (Tables 1 and 2). In addition, Day and Day $\times$ Treatment were significant. This result reflected the significantly greater mortality in Shallow bins on the last $2 \mathrm{~d}$ of the experiment relative to the first day (SNK test, $\mathrm{p}<0.05$ ), whereas no significant difference was found amongst days for Deep bins ( $p>0.05$ ). Despite the Day $\times$ Treatment interaction, a posteriori tests on Treatment differences on each day indicated that mortality was significantly greater in Shallow bins than in Deep bins on each day of the experiment (SNK test, $\mathrm{p}<0.05$; Table 1).

Between 74 and $100 \%$ of the crabs in Shallow bins were consumed within $2 \mathrm{~h}$ of submergence, whereas only 13 to $23 \%$ of the crabs in Deep bins were eaten. The greatest proportion of crabs that could not be accounted for at the end of observations occurred on the first day, when $18 \%$ of the crabs in Deep bins were missing. On this day, only $5 \%$ were missing from the

Table 1 Heloecius cordiformis. Mean number of individuals eaten (per bin) on each day of the experiment (Sep 1985), and results of SNK tests $(p=0.05)$. In parentheses: standard errors; $n$ : number of bins per treatment

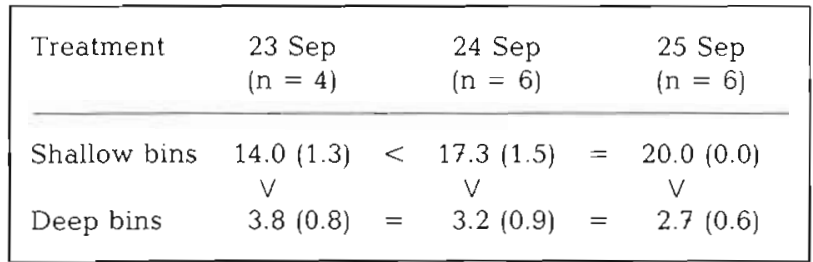

Table 2. Heloecius cordiformis. Analysis of variance of the mean number of individuals eaten in Shallow and Deep bin treatments on each day of the experiment. Data untransformed; Cochran's test not significant ( $p>0.05)$; $n$ : 4 bins per treatment

\begin{tabular}{|lrrrl|}
\hline Source & DF & MS & F & p \\
\hline Day & 2 & 10.8 & 3.9 & $<0.05$ \\
Treatment & 1 & 1334.9 & 476.8 & $<0.001$ \\
D $\times$ T & 2 & 33.8 & 12.1 & $<0.001$ \\
Residual & 18 & 2.8 & & \\
\hline
\end{tabular}

Shallow bins, and, on the following 2 d, less than $1 \%$ were unaccounted for.

Over the $3 \mathrm{~d}$ of the experiment, there was a slight increase in the overall proportion of crabs eaten: $50 \%$ on Day 1, $52 \%$ on Day 2, and $57 \%$ on Day 3. This result may suggest that toadfish feeding on experimental crabs remembered the unusually great abundance of vulnerable crabs on subsequent days and returned to the same area to feed on these days.

Discussion. The results above suggest that entering and remaining in burrows during high tide provides a refuge for Heloecius cordiformis from toadfish and perhaps other subtidal predators. Although between 13 and $23 \%$ of the crabs in Deep bins were preyed upon each day of the experiment, and this treatment more closely approximated 'natural' conditions than Shallow bins, these percentages are almost certainly much greater than natural rates of predation. Firstly, virtually all of the crabs that had been preyed upon in Deep bins comprised those few individuals that failed to construct and occupy a burrow before submergence or had reemerged from burrows after tidal submergence. Either of these occurrences would be very unusual in natural populations (own obs.); therefore, the behaviour of crabs in the experiment suggests that they were affected by the manipulation in such a way as to make them more vulnerable to predation. For example, natural burrows are usually 15 to $25 \mathrm{~cm}$ deep (for crabs of sizes used in this experiment), but burrows could be excavated to only $8 \mathrm{~cm}$ in the experimental bins. Contacting solid substratum might have prompted crabs to re-emerge, perhaps in order to construct a new burrow in a different place or to find an open, unoccupied burrow.

In addition, toadfish might have been attracted to the site because of the unnaturally great abundance of crabs on the surface after tidal submergence. Between 15 and 20 toadfish entered and remained within the $8 \times 3 \mathrm{~m}$ study area throughout the $2 \mathrm{~h}$ observation period, and this density was perhaps 3 to $4 \times$ greater than typical densities (own obs.). Also, at least 1 particular fish (identifiable from its having only 1 eye and scars) was seen at the site on all $3 \mathrm{~d}$.

For both of these reasons (in addition to the fact that reproduction and immigration could not possibly balance such a great rate of predation in nature and thus maintain the population of crabs), observed rates of predation were probably much greater than those occurring in undisturbed populations. This result does not, however, weaken the overall conclusion from the present study that occupying burrows significantly reduces mortality of crabs from predation by toadfish.

During periods of low tide, burrows may provide a refuge against terrestrial and avian predators. Near Sydney, threat from the former is probably less than 
from the latter, however, because mammalian and reptilian predators are uncommon in temperate mangrove swamps. In contrast, mammals, snakes and lizards are documented predators of burrowing crabs in tropical mangrove forests (Magnusson et al. 1976, Cogger 1979). In temperate swamps near Sydney, the most likely predators of import during tidal emersion are the wetland avifauna, including herons, ibises, whimbrels, plovers, curlews and terns (Hutchings \& Recher 1974). In other coastal wetlands, several species of birds are known to feed on fiddler crabs (Colby \& Fonseca 1979, Boshe 1982, Zwarts 1985, Wilson 1989, and others).

When emersed, crabs respond to movements (e.g. an approaching bird or observer) by rapidly jumping into an open burrow. The entry of crabs into their burrows before submergence is, however, not a direct response to the arrival of any immediate threat, but to a particular phase of the tidal cycle. The latter type of behaviour allows crabs to obtain a refuge before the arrival of their subtidal predators, and can therefore be considered avoidance rather than escape. Similar avoidance behaviours, also synchronised with tidal cycles, have been described in various other invertebrates, e.g. gastropods (Hamilton 1976, Garrity \& Levings 1983, Levings \& Garrity 1983, 1984, Warren 1985).

Results from the present study suggest that the probability of a crab without a burrow surviving even a single period of tidal submergence would be very small. Although the selection pressure for digging and occupying burrows before submergence would, therefore, be very strong, some species of crabs do not construct burrows. Some species, like Paragrapsus laevis and Sesarma erythrodactyla, both of which are sympatric with Heloecius cordiformis, do not dig burrows but instead occupy ones excavated by other species (Warren 1987). In Jamaica, Sesarma ricordi and $S$. curacaoense occupy burrows excavated by fiddler crabs or other burrowing species (Warner 1969). In Florida, the mangrove tree crab Aratus pisoni (a grapsid) avoids subtidal predators by climbing trees during high tide and foraging on the mud surface only during low tide (Wilson 1989). Similar behaviour was reported by Macnae (1968) for the grapsids Metopograpsus thukuhar and $M$. frontalis in African and Australian mangrove swamps, respectively. Still other species seek refuge under litter, stones or other debris lying on the surface of the substratum (Hartnoll 1965). All of these species would probably be much more susceptible to predation (as was observed for $H$. cordiformis) were they deprived of access to their refuges.

In conclusion, crabs remaining on the surface of the substratum (or re-emerging onto the surface) after being submerged stand a very small chance of surviving predation by toadfish. Entering and remaining in burrows during high tide, therefore, provides an effec- tive refuge for Heloecius cordiformis from toadfish and perhaps other subtidal predators.

Acknowledgements. I thank Drs K. A. McGuinness, A. J. Underwood, C. Wallace, C. H. Peterson and 2 anonymous reviewers for valuable comments on the manuscript. I also thank the University of Sydney for the Postgraduate Research Award that supported the present investigation.

\section{LITERATURE CITED}

Blundon, J. A., Kennedy, V S. (1982). Refuges for infaunal bivalves from the blue crab, Callinectes sapidus (Rathbun), predation in Chesapeake Bay. J. exp. mar. Biol. Ecol. 65: $67-81$

Boshe, J. I. (1982). Predation of fiddler crabs Uca stenodactyla (Ocypodidae) by the common shorebirds in Pangani Beach, Tanzania. Afr. J. Ecol. 20: 237-240

Cogger, H. G. (1979). Reptiles and amphibians of Australia, 2nd edn. A. H. and A. W. Reed, Sydney

Colby, D. R., Fonseca, M. S. (1979). Application of probability sampling designs for estimation of density and biomass of Uca pugilator. Ann. Rep. Southeast Fish. Ctr. Beaufort Lab., North Carolina, p. 307-321.

Crane, J. (1975). Fiddler crabs of the world. Ocypodidae: Genus Uca. Princeton University Press, New Jersey

Garrity, S. D., Levings, S. C. (1983). Homing to scars as a defense against predators in the pulmonate limpet Siphonana gigas (Gastropoda). Mar. Biol. 72: 319-324

Hamilton, P. V. (1976). Predation on Littorina irrorata (Mollusca: Gastropoda) by Callinectes sapidus (Crustacea: Portunidae). Bull. mar. Sci. 26: 403-409

Hartnoll, R. G. (1965). Notes on the marine grapsid crabs of Jamaica. Proc. Linn. Soc. Lond. 176: 113-147

Hutchings, P. A., Recher, H. F. (1974). The fauna of Careel Bay with comments on the ecology of mangrove and sea-grass communities. Aust. Zool. 18: 99-128

Levings, S. C., Garrity, S. D. (1983). Diel and tidal movement of two co-occurring neritid snails: differences in grazing patterns on a tropical rocky shore. J. exp. mar Biol. Ecol. 67: $261-278$

Levings, S. C., Garrity, S. D. (1984). Grazing patterns in Siphonaria gigas (Mollusca, Pulmonata) on the rocky Pacific coast of Panama. Oecologia (Berl.) 64: 152-159

Macnae, W. (1968). A general account of the fauna and flora of mangrove swamps and forests in the Indo-West Pacific Region. Adv. mar. Biol. 6: 73-270.

Magnusson, W E., Webb, G. J. W., Taylor, J. A. (1976). Two new locality records, a new habitat and a nest description for Xeromya myoides Thomas (Rodentia: Muridae). Aust. Wild. Res. 3: 153-157

Montague, C. L. (1980). A natural history of temperate western Atlantic fiddler crabs (genus $U c a$ ) with reference to their impact on the salt marsh. Contrib. mar. Sci. 23: 25-55

Virnstein, R. W (1977). The importance of predation by crabs and fishes on benthic fauna in Chesapeake Bay. Ecology 58: 1199-1217

Warner, G. F. (1969). The occurrence and distribution of crabs in a Jamaican mangrove swamp. J. Anim. Ecol. 38: 379-389

Warner, G. F. (1977). The biology of crabs. Van Nostrand Reinhold, New York 
Warren, J. H. (1985). Climbing as an avoidance behaviour in the salt marsh periwinkle, Littorina irrorata (Say). J. exp mar. Biol. Ecol. 89: 11-28

Warren, J. H. (1987). Behavioural ecology of crabs in temperate mangrove swamps. Ph.D. thesis, University of Sydney Warren, J. H., Underwood, A. J. (1986). Effects of burrowing

This note was presented by Professor C. H. Peterson, Morehead City, North Carolina, USA crabs on the topography of mangrove swamps in New South Wales. J. exp. mar. Biol. Ecol. 102: 223-235

Wilson, K. A. (1989). Ecology of mangrove crabs: predation, physical factors and refuges. Bull. mar Sci. 44: 263-273

Zwarts, L. (1985). The winter exploitation of fiddler crabs UCa tangeri by waders in Guinea-Bissau. Ardea 73: 3-12

Manuscript first received: April 17, 1990

Revised version accepted: July 24, 1990 